\title{
Energy Input-Output Analysis for Production of Selected Crops in the Central Clay Vertisols of Gezira Agricultural Scheme (Sudan)
}

\author{
Abdalla N. O. Kheiry ${ }^{1}$, Mohamed H. Dahab ${ }^{2}$ \\ ${ }^{1}$ Department of Agricultural Engineering - College of Agriculture - University of Khartoum (Khartoum- Sudan) \\ E-mail: abdallakheiry@gmail.com \\ ${ }^{2}$ Department of Agricultural Engineering - Faculty of Agriculture- University of Khartoum- Shambat-Sudan \\ E-mail: mhdahabahmed55@yahoo.com
}

\begin{abstract}
The main objective of this study was to analyze the energy input, energy output and energy output/input ratio of three selected crops viz, sorghum, wheat and cotton in Gezira agricultural scheme of Sudan during five growing seasons. The results showed that the total energy expenditures (input) were $12.64 \mathrm{GJ} / \mathrm{ha}, 18.52 \mathrm{GJ} / \mathrm{ha}$ and $18.72 \mathrm{GJ} / \mathrm{ha}$, while the total energy outputs were 95.59 GJ/ha, $127.90 \mathrm{GJ} / \mathrm{ha}$ and $20.51 \mathrm{GJ} / \mathrm{ha}$ for sorghum, wheat and cotton respectively. Fertilizer application was the most energy consuming field operation for the three crops. It was about $52-68 \%$ of total energy inputs. Energy output/input ratios varied from 6.2-8.4 for sorghum, 5.9-7.4 for wheat and 0.9-1.2 for cotton. Linear relationship was found between crop production and energy output/input ratios with high correlations $(R 2=0.97-99)$ for the three crops.
\end{abstract}

Keywords: Energy, input, output, energy ratio, vertisols, Gezira

\section{Introduction}

Agriculture is an important sector for production of food and raw materials in un-developed and developing countries. It is both consumer and producer of energy. All agricultural operations require energy in one form or another, human labour, animal power, fertilizer, machinery, chemicals, fuel and electricity.

To meet the growing demand of the increasing population and exports, the productivity of land to be increased, this would substantially require higher energy input and better management of production system [1]. Therefore, in order to sustain agricultural production, effective energy use is required, since it provides ultimate financial saving, preservation of fossil resources and reduction of environmental distortion [2].

Energy required in agricultural are divided into direct energy for performing various tasks related to crop production in the fields and indirect energy, which is not directly used on the farms such as fertilizer, seed and chemicals. Also it may be grouped into physical, chemical and biological energy. Many researches have studied energy use in agriculture and economic analysis to determine the energy use efficiency for crop production in many countries [3, 4, 5, 6, 7].

Energy utilization in farm level usually varies with farm size, crop growing, production practices and physical environmental [8]. A study showed no evidence that crop yield could be affected by the type of energy source used in a farm and that increase in yield was the integrated effect of all inputs. However, availability of mechanical power for high rate of application in specific time permitted farmers to use different production strategies and thus resulted in increased food and crop production. By the increase need for higher productivity per unit area and brining additional areas under high yielding crops, it is inevitable that the share of agriculture in the national energy consumption would increase $[9,10]$.

Sudan is ranked as one of the world greatest potential areas for agricultural production and the estimated arable land for agriculture is more than 8.4 million hectares, which is equivalent to about $32 \%$ of total arable land in Africa [11]. Out of this potential area only $20 \%$ is currently under cultivation. This cultivated area can be mainly classified into irrigated and rain-fed sectors. The main crops grown in these sectors are cotton, sorghum, millet, sesame, wheat, G/N and sunflower. The energy used for carrying out the field operations for production of most crops is derived from human, animal and mechanical power. It is mainly used for land preparation, planting, weeding, spraying, fertilizer application, harvesting and transportation.

Although most of energy input resources are used for crop production in Sudan, but still the output of these crops is low. This may need better energy input and production systems management for improved use of energy resources and higher yields. The study was intended to assess the energy inputs during field activities for different farm operations and the energy outputs for production of three crops, sorghum, wheat and cotton.

\section{Materials and Methods}

The primary data for energy input resources were collected by field surveys and personal interview of farmers and agricultural engineers through questionnaire. Secondary data for energy input resources and energy outputs were obtained from the available information in literatures and other resources (Table 1). 


\section{International Journal of Science and Research (IJSR) \\ ISSN (Online): 2319-7064 \\ Index Copernicus Value (2013): 6.14 | Impact Factor (2014): 5.611}

The major three crops planted in the Gezira area were selected viz, cotton as an export crop, wheat and sorghum as food crops for human and animals. All the three crops are produced in the scheme by surface irrigation.

The data collected for each crop included energy input resources for different farm operations, from land preparation up to crop harvesting. For the purpose of computation and energy analysis, three groups of energy resources were considered namely physical, chemical and biological energy as both direct and indirect energy inputs [12].

For energy computation purposes the following assumption were made:

a. One hour work by a person was assumed to be equivalent to $0.075 \mathrm{~kW}$.ha energy.

b. One man-day was equivalent to 8 hrs work.

c. Energy output of a diver was negligible compared to energy input of a tractor.

d. The operation carried out and energy inputs during the study period $(200 / 01$ - 2004/05) were assumed the same.

Based on these assumptions, the energy consumptions were estimated.

Computation of energy inputs:

*Total energy inputs $(\mathrm{MJ} / \mathrm{ha})=\sum($ physical + chemical + biological).

1- Physical energy inputs (MJ/ha)

Physical energy input $=\sum$ (human labour + mechanical power)

a) Human energy inputs $=\sum(0.27 \times \mathrm{Md} \times \mathrm{Wh})$

Where;

Md = number of man-days/ha for field operations

Table 1: Energy equivalents of different input and outputs

\begin{tabular}{|l|l|l|l|}
\hline \multicolumn{2}{|c|}{ Inputs $\left(\mathrm{MJkg}^{-1}\right)$} & \multicolumn{2}{c|}{ Outputs $\left(\mathrm{MJkg}^{-1}\right)$} \\
\hline 1. Seed & 14.7 & i) Sorghum & 15.7 \\
\hline i) Sorghum & 14.7 & ii) Wheat & 14.7 \\
\hline ii) Wheat & 25.0 & iii) Cotton & 11.8 \\
\hline iii) Cotton & 2. By-product \\
\hline 2. Agrochemicals & i) Sorghum straw & 15.7 \\
\hline i) Nitrogen & 75.4 & ii) Wheat straw & 15.8 \\
\hline ii) Phosphorus & 17.4 & iii) Cotton seed & 25.0 \\
\hline $\begin{array}{l}\text { iii) Pesticides } \\
\text { 3. Mechanical power }\end{array}$ & \\
\hline i) Diesel & $47.8 \mathrm{MJL}^{-1}$ & & \\
\hline ii) Machinery & 86.8 & & \\
\hline $\begin{array}{l}\text { 4. Human } \\
\text { labour }\end{array}$ & $0.27 \mathrm{MJhr}^{-1}$ & & \\
\hline
\end{tabular}

Source; $[1,5,13]$

Wh = number of working hrs/man-day
$0.27=$ conversion factor $(\mathrm{MJ} / \mathrm{hr})$

b) Mechanical energy input $(\mathrm{MJ} / \mathrm{ha})=\sum$ (fuel + sequester $)$

- Fuel energy $(\mathrm{MJ} / \mathrm{ha})=\sum(\mathrm{FC} \times \mathrm{EEd})$

Where;

$\mathrm{FC}=$ fuel consumption rate of machine in operation (L/ha).

EEd = energy equivalent of diesel fuel $(\mathrm{MJ} / \mathrm{L})$

- Energy sequestered in mechanical power $=\Sigma[(\mathrm{MW} \times$ EEs)/Aa]

Where;

MW = weight of machinery $(\mathrm{kg})$

EEs = energy equivalent in sequester $(\mathrm{MJ} / \mathrm{kg})$

Aa $=$ annual planted area (ha)

2- Chemical energy inputs ( $\mathrm{MJ} / \mathrm{ha})$

Chemical energy inputs $(\mathrm{MJ} / \mathrm{ha})=\sum($ Fert. energy + pesti. energy)

- Fertilizer energy $(\mathrm{MJ} / \mathrm{ha})=\sum($ Fert. Rate $\times$ EEf $)$

Where;

Fert. Rate $=$ fertilizer application rate $(\mathrm{kg} / \mathrm{ha})$

$\mathrm{EEf}=$ energy equivalent of fertilizer $(\mathrm{MJ} / \mathrm{kg})$

- Pesticide energy $(\mathrm{MJ} / \mathrm{ha})=\sum($ Pesti Rate $\times$ EEp $)$

Where;

Pesti. Rate $=$ pesticide application rate $(\mathrm{kg} / \mathrm{ha})$

$\mathrm{EEp}=$ energy equivalent of pesticide $(\mathrm{MJ} / \mathrm{kg})$

3- Biological energy inputs (MJ/ha)

Biological energy inputs $(\mathrm{MJ} / \mathrm{ha})=($ Seed appl $\times$ EEsd $)$.

Where;

Seed appl. = seed application rate $(\mathrm{kg} / \mathrm{ha})$

EEsd $=$ energy equivalent of seed $(\mathrm{MJ} / \mathrm{kg})$

Computation of energy output:

Total energy output was considered as main product plus by-product.

Total energy output $(\mathrm{MJ} / \mathrm{ha})=($ Crop yld $\times$ EEy $)+($ byproduct $\times$ EEb)

Where;

Crop yld = crop yield $(\mathrm{kg} / \mathrm{ha})$

EEy = energy equivalent of crop yield $(\mathrm{MJ} / \mathrm{kg})$

$\mathrm{EEb}=$ energy equivalent of crop by-product $(\mathrm{MJ} / \mathrm{kg})$

Energy use efficiency:

It is the ratio between total energy output and total energy input. Based on the energy equivalents of the inputs and output, the energy ratio (energy use efficiency) calculated as in this relation [14]. 
Energy use efficiency $=$

Total output energy (MJ/ha) / Total input energy (MJ/ha)

\section{Results and Discussion}

The human energy computation based on man-days required to perform the different operations for crop production. The man-days requirement for production of sorghum, wheat and cotton after conversion into hours of work is given in table 2 .

Table 2: Man-days and hours of work required per hectare for the different farm operation of the three crops

\begin{tabular}{|c|c|c|c|c|c|c|}
\hline \multirow{2}{*}{ Field operations } & \multicolumn{2}{|l|}{ Sorghum } & \multicolumn{2}{|l|}{ Wheat } & \multicolumn{2}{|l|}{ Cotton } \\
\hline & man-days/ha & hrs/ha & man-days/ha & hrs/ha & man-days/ha & $\mathrm{hrs} / \mathrm{ha}$ \\
\hline Sowing & 7 & 56 & 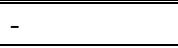 & 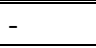 & 7 & 56 \\
\hline 1st weeding & 14.0 & 115 & 7 & 57.7 & 5 & 40 \\
\hline 2nd weeding & 9.5 & 77 & 5 & 40 & 14 & 115 \\
\hline Irrigation & 9.5 & 77 & 12 & 96 & 19 & 153.5 \\
\hline Fertilizer app. & 2.5 & 20 & 5 & 40 & 5 & 40 \\
\hline Cutting + threshing & 14.0 & 115 & 2 & 16 & - & - \\
\hline Picking & - & - & - & - & 43 & 345.5 \\
\hline Total & 56.5 & 460 & 31 & 249.5 & 93 & 750 \\
\hline
\end{tabular}

Source; [15]

Contribution of energy input components in farm operations for production of the three crops is shown in Figure 1.

It shows that energy input varied with the sources and for the crop cultivated. The chemical energy inputs contribution was the highest for the three crops (53-75\%) compared with physical and biological energy inputs (Fig.2). This is in agreement with the output of [1]. The highest physical energy inputs (37.5\%) was for wheat which means more mechanization compared to the other two crops, while the highest chemical energy input was for cotton $(75.5 \%)$.

Physical energy input for farm operations:

Human energy input constitute the least portion for the three crops $(0.5-1.0 \%)$, although, human power used in most farm operation. The labour working hours required per hectare for the three crops varied from $249-750$ (Table2). The mechanical energy (fuel + machinery sequester) input for production of the three crops was varied, it was $4.0 \mathrm{GJ} / \mathrm{ha}$ for cotton, $4.2 \mathrm{GJ} / \mathrm{ha}$ for sorghum and $6.8 \mathrm{GJ} / \mathrm{ha}$ for wheat.

The contribution of mechanical input energy was generally higher for the three crops compared to the human energy and this is in line with the finding of $[1,7]$.

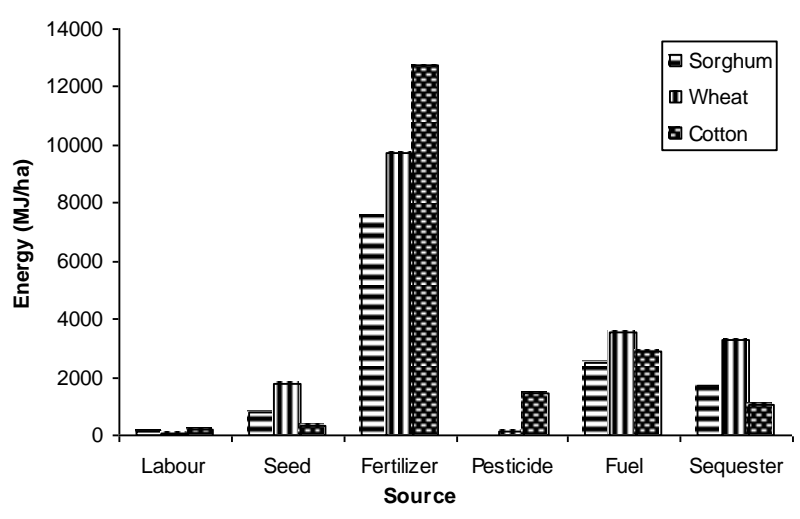

Fig. 1 Energy input sources for sorghum, wheat and cotton crops

[a]

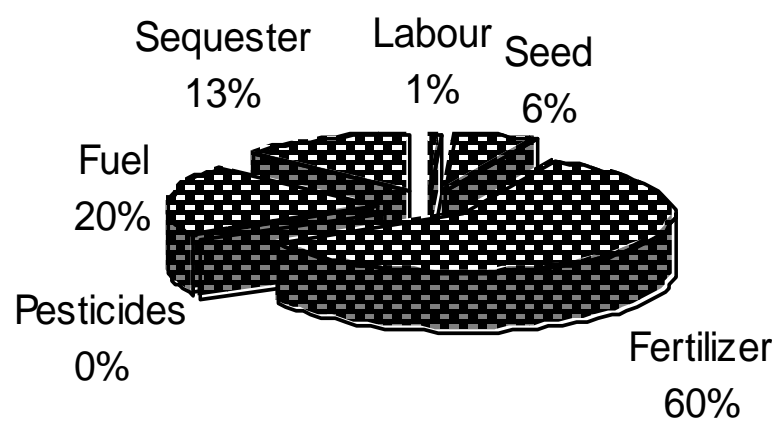




\section{International Journal of Science and Research (IJSR) \\ ISSN (Online): 2319-7064 \\ Index Copernicus Value (2013): 6.14 | Impact Factor (2014): 5.611}

(b)
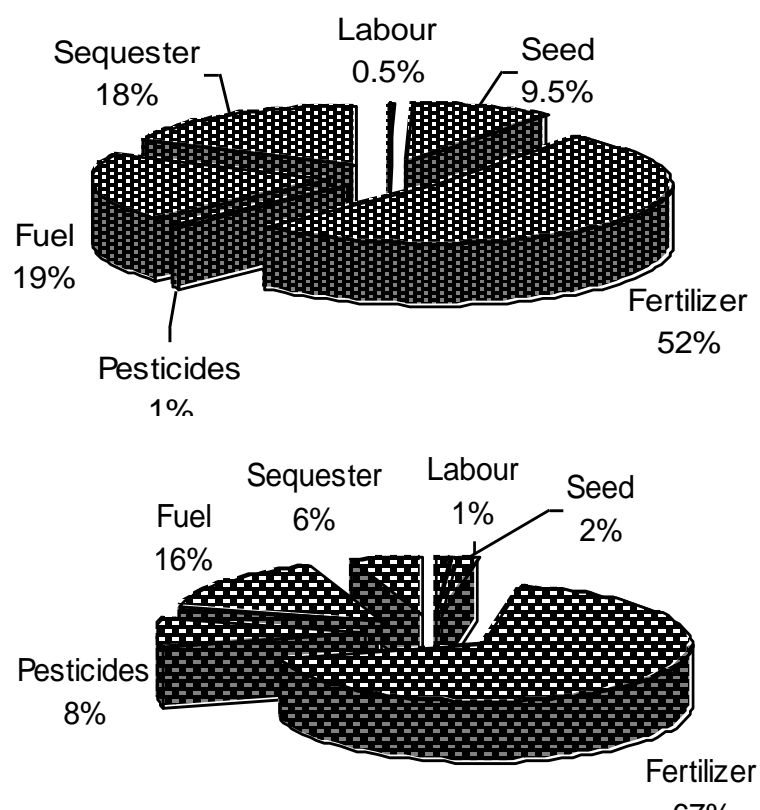

$67 \%$

Fig. 2 Energy input percentages for (a) sorghum (b) wheat (c) cotton crop production

The mechanical energy input (fuel and machinery sequester) accounts for $33 \%$ of wheat and $22 \%$ of cotton production energy input in Gezira scheme. The major part of this energy is associated with land preparation. Selection of suitable tillage system, timing of tillage operation and matching of energy sources with the implements used could help in energy savings. The highest physical energy input was $6.9 \mathrm{GJ} / \mathrm{ha}$ for wheat followed by sorghum $4.3 \mathrm{GJ} / \mathrm{ha}$ and then cotton $4.2 \mathrm{GJ} / \mathrm{ha}$. Out of this energy, the contribution of human labour for production of sorghum, wheat and cotton was $0.12 \mathrm{GJ} / \mathrm{ha}, 0.07 \mathrm{GJ} / \mathrm{hr}$ and $0.20 \mathrm{GJ} / \mathrm{hr}$ respectively. The variations in physical energy input between crops mainly depended on farm operations carried out and types of machinery used. Land preparation and harvesting operations mainly demanded higher physical energy input.

Contribution of human energy input for wheat production was less than that of sorghum and cotton, and this may be probably for higher mechanization levels used for production of this crop compared to other two crops [1].

Material energy inputs for farm operations:

Material energy inputs for field operations included chemical energy from fertilizer and pesticides and biological energy from seeds. Fig.1 shows that material energy inputs for production of the three crops was the highest compared to other sources. Its contribution ranged from $53 \%$ out of total input energy for wheat, $60 \%$ for sorghum and up to $75 \%$ for cotton. Energy input from fertilizer remained the highest contributor for the three crops. It was $7.5 \% \mathrm{GJ} / \mathrm{ha}$ for sorghum, $9.7 \mathrm{GJ} /$ ha for wheat and $12.8 \mathrm{GJ} /$ ha for cotton. Fertilizers are energy intensive especially nitrogen fertilizer which is used for production of most crops.

Total energy inputs for the three crops:

Total energy input for production of the three crops varies between $18.7 \mathrm{GJ} / \mathrm{ha}$ for cotton production followed by wheat $18.5 \mathrm{GJ} / \mathrm{ha}$ and then sorghum $12.6 \mathrm{GJ} / \mathrm{ha}$. Total energy inputs for the three crops with their main resources are shown in Fig. 3. It can be observed that fertilizer was the main cause of variation of total energy input for the three crops. This is in line with the findings of $[1,13])$.

Total energy output for different crops:

Total energy output included the main product and byproduct of the crop. The total areas cultivated and production of the three crops during the five season period of study (2001-2005) is shown in Fig. 4. During these five seasons of study, crop production and area cultivated of the three crops was varied. The total energy output for wheat crop was the highest (average $127.9 \mathrm{GJ} / \mathrm{ha}$ ) followed by sorghum (average $95.6 \mathrm{GJ} / \mathrm{ha}$ ) and then the lowest was cotton (average $20.5 \mathrm{GJ} / \mathrm{ha}$ ).

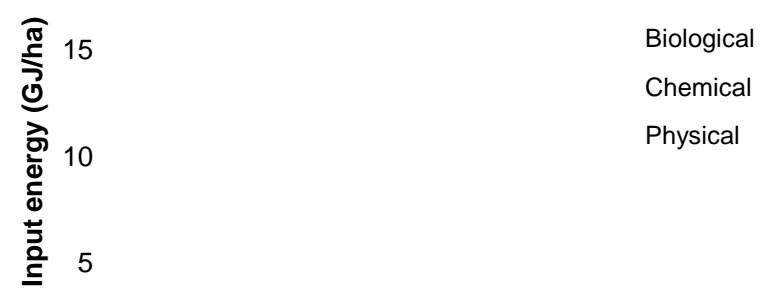

0

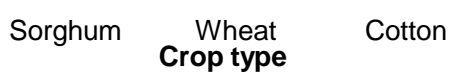

Fig. 3 Total input energy resources (GJ/ha) for the three crops

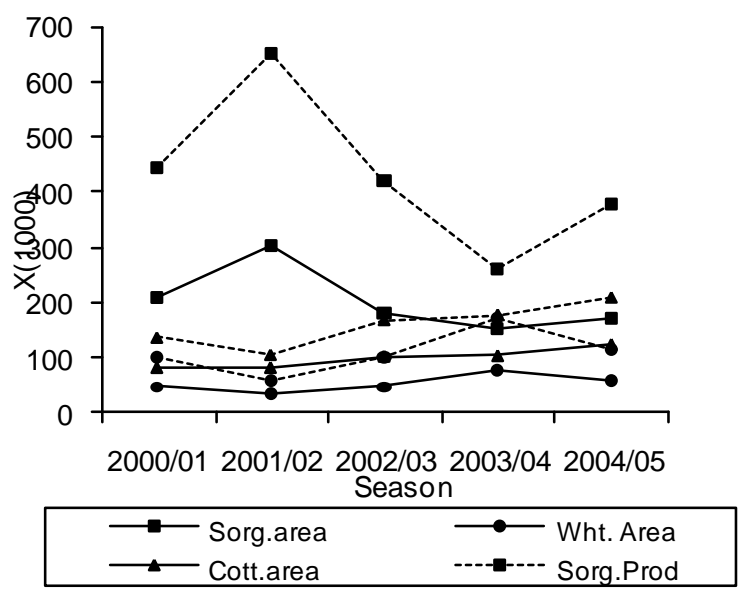

Fig. 4 Area planted and corresponding production for Sorghum, Wheat and Cotton 


\section{International Journal of Science and Research (IJSR) \\ ISSN (Online): 2319-7064}

Index Copernicus Value (2013): 6.14 | Impact Factor (2014): 5.611

Energy use efficiency:

Energy ratio for the three crops varied between $0.9-8.4$ (Fig. 5). The highest energy ratios during the period of study were recorded by the sorghum crop (6.2 - 8.4) followed by wheat crop (5.9 - 7.4), while the lowest was recorded by the cotton crop $(0.4-1.2)$. High energy ratios were corresponding to high energy use efficiency which could be due to higher energy outputs or lower inputs. Energy ratio was found highly correlated with crop production per hectare for the three crops $\left(R^{2}=0.97-\right.$ 0.99 ) and making linear relationships as follows:

Sorghum $\mathrm{Y}=0.32 \mathrm{x}-0.25$, Wheat $\mathrm{Y}=0.34 \mathrm{x}-0.32$, Cotton $\mathrm{Y}=1.67 \mathrm{x}-0.27$

Where; $\mathrm{x}=$ energy output/input ratio, and $\mathrm{Y}=$ crop production (t/ha)

These findings are in line with those of [16].

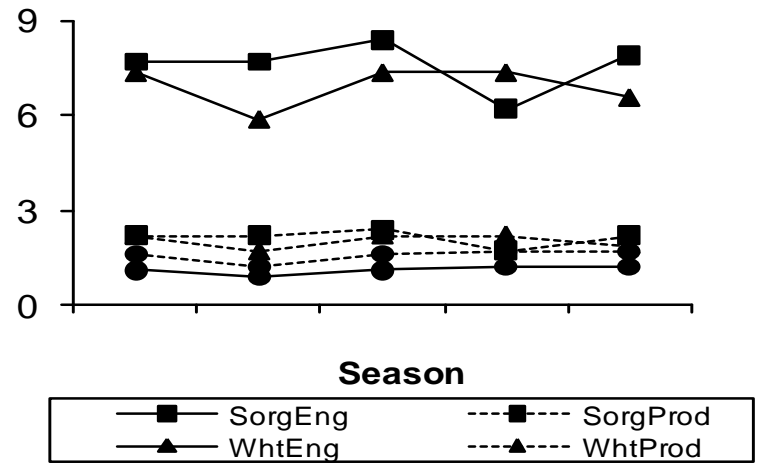

Fig. 5 Energy ratio versus production (t/ha) for Sorghum, Wheat and cotton

\section{Conclusion}

- Analysis of energy inputs for the three crops showed that energy input from fertilizer and mechanical power was the highest and the share of labor energy was very low.

- There is a linear relationship between energy output/input ration and crop production, which means that methods of farming with high energy output/input ratio must be used to accomplish greater production.

- Energy savings may be possible by using lower recommended doses of fertilizers and proper timing of field operations and matching the size and power of tractor with machinery for field operations.

- Since the energy inputs for production of crops is looking high, it is important to suggest methods and policies that may reduce the negative effect of high energy inputs such as pollution, global warming and to develop more efficient, economical and environment friendly agricultural production systems that increase energy use efficiency.

\section{Acknowledgment}

This work was supported in part by:

- Special Fund for Agroscientific Research in the Public Interest(No.201503117),

- By The "National Science \& Technology Support Program in the 12th Five Year Plan of China (No.2013BAD08B01-3)" ,

- By the "Key Lab of Soil-Machine-Plant System Technology of Ministry of Agriculture"

\section{References}

[1] A. Chamsing, V.M. Salokhe and G. Singh. "Energy Consumption analysis for selected crops in different regions of Thailand". Agric. Engineering International: The CIGR Ejournal, vol. 8, pp.1-18, 2006.

[2] V. Demircan, K. Ekinci, H.M. Keenar, D. Akbotat and C. Ekinic."Energy and economic analysis of sweet cherry production in Turkey: A case study from Isparta Province”. Energy Conversion and Mgt., Vol. 47, pp. 1761-1769, (2006).

[3] C.L. Thakur and G.r. Makan. "Energy Scenarios of Madhya Pradesh (India) agriculture and future requirements". Energy Conversion Mgt., vol.38, pp. 237-244, (1997).

[4] M.A. Khan and G. Singh., "Energy inputs and potential for agricultural production in Western Pakistan.Agricultural systems", vol. 54, pp. 341-356, (1997).

[5] B. Ozkan, H. Akcaoz and C. Fert. "Energy input output analysis in Turkish agriculture. Renewable Energy", vol. 29, pp. 39-51, (2004).

[6] M.S. Alam, M.R. Alam and K.K "Islam. Energy flow in agriculture," Bangladesh. American J. of Environ. Sci., vol. 1 pp. 213-220, (2005).

[7] M. Karimi, P.A. Rajabi and A. Borghei. "Energy analysis of sugarcane production in plant farms: A case study in Debel Khazai Agro-Industry in Iran". American - Eurasian J. Agric. and Environ. Sci., vol. 4, pp. 165-171 (2008).

[8] R.L. Sarker. "Energy use pattern in small farm systems of Bangladesh". J. Agric. and Mech. Vol, 4, pp. 20-44, (2000).

[9] S. Singh, S.R. Verma, and J.P. Mittal ".Energy requirements for production of major crops in India”. Agricultural Mechanization in Asia, Africa and Latin America (AMA), vol. 28, pp. 13-18, (1997).

[10]K.O. Esengun, O. Gunduz, and G. Erdal. "Inputoutput energy analysis in dry apricot production of Turkey”. Energy Conversion Mngt., vol. 48, pp. 592598, (2007).

[11] A.A. Abdalla and H.O. Abdel Nour. "The agricultural potentials of Sudan. Exclusive" Intelligence Review Khartoum, Sudan, 2004.

[12] G. Singh, C.P. Bohra and B.K. dav. "Energy input in production agriculture of India during last four decades". Agricultural Engineering Journal, vol. 3, p. 1-20, (1994).

[13]H.A. Khan and S.M.A. Hossain. "Study on energy input, output and energy use efficiency of major jute 
based cropping pattern". Bangladesh J. Sci. Ind. Res., vol. 42, pp. 195-202 (2007).

[14] M.M. Canakci, I. Topakci, and A. Ozmerzi. "Energy use pattern in some field crops and vegetable production: case study for Antalya region", Turkey. Energy Conversion Mngt., vol. 46 pp. 655- 666, (2005).

[15] M.I. Mohamed,"Physical energy estimation for crop production in the central clay of Gezira Scheme Sudan”. Unpublished M.Sc. dissertation, Faculty of Agriculture, Shambat, University of Khartoum, Sudan, 2007.

[16] A.K. Mahapatra, R. Tsheko, K.L. Kumar and P. "Chipasha. Physical energy input for maize production in Zambia". Agricultural Mechanization in Asia, Africa and Latin America (AMA),vol. 34 pp. 57-60, (2003).

\section{Author Profile}

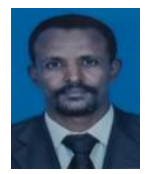

Dr. Abdalla Noureldin Osman Kheiry, place and date of birth Khartoum Nourth, Sudan, 11/3/1974. B.Sc and M. Sc. Advisor and Ph.D Co - Advisor. Assistant Professor at Agricultural Engineering, College of Agricultural Studies, Sudan University of Science and Technology, Shambat, Sudan. The main field of specialization is Agricultural Engineering, while the specific area of specialization is Farm power and agricultural Machinery. The main areas of my research interest are; Agricultural machine design, Tillage implements field evaluation and Farm tractor performance and Tillage systems management, Energy input-output analysis for production of field crops, Spatial variation of soils and precision farming and Animal traction for rural and small farmers. About 10 Refereed papers are published in precise scientific international and national periodicals and one Cartoon text Books in Arabic. Member of two professional associations and Societies.

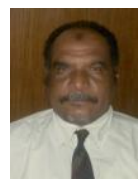

Professor Mohamed Hassan Dahab, Ph. D Adviser. Place and date of birth Wadi Halfa, North of Sudan, 1/1/1960 Professor of Agricultural Engineering, Faculty of Agriculture, University of Khartoum, Shambat, Sudan. The main field of specialization is Agricultural Engineering, while the specific area of specialization is Farm power and Machinery Management. The main areas of my research interest are; Farm tractor performance and management, Tillage implements field evaluation, Tillage systems management, Computer modeling and programming for farm machinery management and selection, Energy input-output analysis for production of field crops, Spatial variation of soils and precision farming and Animal traction for rural and small farmers. More than 40 Refereed papers are published in precise scientific international and national periodicals and three text Books in Arabic. Member of five professional associations and Societies. 